\title{
Ligation of Internal Iliac Artery: Educational Video with Basic Steps and Key Points
}

\author{
(1) Illker SELÇUKa, \\ (D) Çağrı GÜLÜMSER ${ }^{a}$, \\ Di ilkan TATAR ${ }^{b}$, \\ Deniz DEMIRYÜREK ${ }^{b}$ \\ aUniversity of Health Sciences \\ Zekai Tahir Burak Woman's Health \\ Training and Research Hospital, \\ bDepartment of Anatomy, \\ Hacettepe University Faculty of Medicine, \\ Ankara, TURKEY \\ Received: 09 May 2019 \\ Received in revised form: 09 Jul 2019 \\ Accepted: 10 Jul 2019 \\ Available online: 22 Oct 2019 \\ Correspondence: \\ Illker SELÇUK \\ University of Health Sciences \\ Zekai Tahir Burak Woman's Health \\ Training and Research Hospital, \\ Ankara, TURKEY \\ ilkerselcukmd@ hotmail.com
}

For the video/videos of the article:

Copyright $@ 2019$ by Türkiye Klinikleri

\begin{abstract}
Internal iliac artery, the pelvic branch of the common iliac artery, supplies the pelvic viscera. Bilateral ligation of the internal iliac artery is often practiced in obstetrics and gynecology as it helps in controlling massive pelvic bleeding. The ligation of this artery just after the posterior division is crucial. In this video, we present a cadaveric dissection, where the distance between the bifurcation of the common iliac artery and the superior gluteal artery was found to be $3.1 \mathrm{~cm}$. The video includes the demonstration of relevant anatomic structures and is aimed at educating the residents and gynecologists regarding the steps and key points to be kept in mind during internal iliac artery ligation.
\end{abstract}

Keywords: Internal iliac artery; hypogastric; bleeding; obstetrics; cadaveric

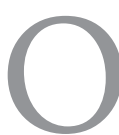

ver the pelvic brim, anterior to the sacroiliac joint, at the level of the first sacral vertebra (S1), the common iliac artery divides into two branches. External iliac artery, which is a direct extension, lies medial to the psoas major muscle; and once the artery advances inferior to the inguinal ligament, its distal continuation comes to be known as the femoral artery. Internal iliac artery courses inferiorly, downwards to the level of the greater sciatic foramen. It is the main artery supplying blood to the uterus, vagina, bladder, and urethra via the anterior division (internal pudendal artery, inferior gluteal artery, obturator artery, uterine artery, superior vesical artery, inferior vesical artery, middle rectal artery). The posterior division (superior gluteal artery, ilio-lumbar artery and lateral sacral artery) supplies blood mainly to the gluteal region, medial thigh and hip joints. ${ }^{1,2}$

Branching pattern of the internal iliac artery varies greatly. Nevertheless, superior gluteal artery and other branches of the posterior division arise from the same trunk in a majority of the patients (62\%), bearing an average length of $2.7 \mathrm{~cm}$ from the point of bifurcation of the common iliac artery (ranging between 2-3.5 cm). ${ }^{3,4}$ This cadaveric dissection study found the distance between the bifurcation of the common iliac artery and the origin of the superior gluteal artery to be $3.1 \mathrm{~cm}$. For most patients, the ligation of the internal iliac artery $3 \mathrm{~cm}$ away from the bifurcation of the common iliac artery is a safe idea. 
During massive peripartum bleeding or intractable pelvic hemorrhage, bilateral ligation of internal iliac artery helps decrease the blood volume flowing to the pelvis, with a definite success rate. However, there are some key points that must be kept in mind during ligation of the internal iliac artery. Thorough knowledge of retroperitoneal anatomic structures and good practical exposure would help make the procedure easier. Despite these advantages, in patients with obesity and a large uterus, the approach becomes difficult. $^{5}$

This educational video demonstrates the relevant anatomic structures and key points involved in the ligation technique for the internal iliac artery. It aims to enlighten the residents and pelvic surgeons.

\section{SURGICAL TECHNIQUE}

\section{STEPS AND KEY POINTS OF INTERNAL ILIAC ARTERY LIGATION (FIGURE 1)}

Entry is gained into the retroperitoneum, by piercing the lateral parietal peritoneum between the infundibulopelvic ligament (ligamentum suspensorium ovarii) and round ligament (ligamentum teres uteri). The Psoas major muscle is exposed.

The incision is extended parallel to the infundibulopelvic ligament up to the level of promontorium.

Key point 1: The ureter is identified at the base of the posterior sheet of the broad ligament (ligamentum latum uteri); in case not found completely,

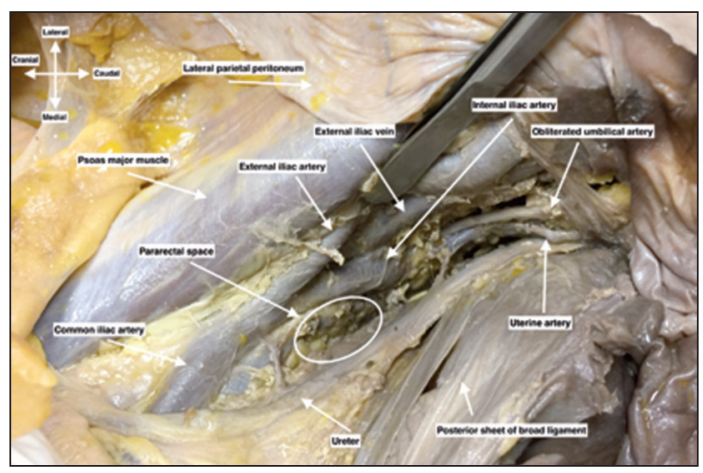

FIGURE 1: Left pelvic sidewall and retroperitoneal anatomic structures. it implies that the ureter has crossed over the common iliac artery and this point would be used in detection of ureter.

Key point 2: Pararectal space is expanded (anterior to the sacrum), the medial border is represented by the ureter and the lateral border is made up of the internal iliac artery. This establishes a secure zone for the ureter.

The internal iliac artery is revealed and if not observed clearly, the fibro-fatty tissue covering it and the surrounding fascia is gently removed. This maneuver elevates the internal iliac artery from the underlying internal iliac vein.

Key point 3: Right-angled clamp is passed inferior to the internal iliac artery from the lateral side to the medial. This prevents a probable injury to the external iliac vein which lies on the lateral surface of the internal iliac artery. A resistance while passing the right-angled clamp implies that the surrounding fascia has not been removed adequately. The passive finger must be used to stabilize the internal iliac artery by pressing on it and a meticulous dissection must then be performed around the internal iliac artery to improve the passage of the right-angled clamp. This maneuver prevents a probable injury to the internal iliac vein that is positioned inferior to the internal iliac artery.

The internal iliac artery is ligated distal to the origin of the posterior division with number 1 vicryl suture.

This cadaveric dissection study reveals that the branch of the superior gluteal artery (the main branch of the posterior division of internal iliac artery) occupies $3.1 \mathrm{~cm}$ of the entire $4.9 \mathrm{~cm}$ length of the internal iliac artery.

\section{Acknowledgement}

This cadaveric dissection was performed at Hacettepe University Faculty of Medicine Department of Anatomy.

\section{Informing}

Due to the presence of the name of the journal editor's among the authors, the assessment process of the study was conducted by the guest editor. 


\section{Source of Finance}

During this study, no financial or spiritual support was received neither from any pharmaceutical company that has a direct connection with the research subject, nor from a company that provides or produces medical instruments and materials which may negatively affect the evaluation process of this study.

\section{Conflict of Interest}

No conflicts of interest between the authors and / or family members of the scientific and medical committee members or members of the potential conflicts of interest, counseling, expertise, working conditions, share holding and similar situations in any firm.

\section{Authorship Contributions}

Idea/Concept: İlker Selçuk, Çağrı Gülümser; Design: İlker Selçuk; Control/Supervision: İlkan Tatar, Deniz Demiryürek; Literature Review: İlker Selçuk; Writing the Article: İlker Selçuk, Çağrı Gülümser; Critical Review: İlkan Tatar, Deniz Demiryürek.
1. Selçuk I, Ersak B, Tatar İ, Güngör T, Huri E. Basic clinical retroperitoneal anatomy for pelvic surgeons. Turk $\mathrm{J}$ Obstet Gynecol. 2018;15(4):259-69. [Crossref] [PubMed] [PMC]

2. Selçuk I, Yassa M, Tatar I, Huri E. Anatomic structure of the internal iliac artery and its educative dissection for peripartum and pelvic hemorrhage. Turk J Obstet Gynecol.

\section{REFERENCES}

2018;15(2):126-9. [Crossref] [PubMed] [PMC]

3. Bleich AT, Rahn DD, Wieslander CK, Wai CY, Roshanravan SM, Corton MM. Posterior division of the internal iliac artery: anatomic variations and clinical applications. Am J Obstet Gynecol. 2007;197(6):658.e1-5. [Crossref] [PubMed]

4. Mamatha $\mathrm{H}$, Hemalatha B, Vinodini P, Souza AS, Suhani S. Anatomical study on the varia- tions in the branching pattern of internal iliac artery. Indian J Surg. 2015;77(Suppl 2):24852. [Crossref] [PubMed] [PMC]

5. Selçuk I, Uzuner B, Boduç E, Baykuş $Y$, Akar B, Güngör T. Step by step ligation of internal iliac artery. J Turk Ger Gynecol Assoc. 2019;20(2):123-8. [Crossref] [PubMed] [PMC] 